\begin{tabular}{|c|c|}
\hline 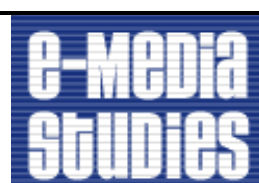 & $\begin{array}{l}\text { Journal of e-Media Studies } \\
\text { Volume I, Issue 1, Spring } 2008 \\
\text { Dartmouth College }\end{array}$ \\
\hline
\end{tabular}

\title{
Horace Newcomb in conversation with Tara McPherson
}

\section{(Summer 2007)}

Horace Newcomb <http://www.grady.uga.edu/CV/Newcomb.2005.pdf > published the first edition of Television: The Critical View in 1976. The work is now in its 7th edition and has long served as a touchstone for television studies, evolving along with the field. Newcomb himself is a pioneer of the discipline, having authored TV: The Most Popular Art in 1974 and going on to co-author, with Robert Alley, The Producer's Medium (1983), and edit two editions of ,The Encyclopedia of Television <http://www.museum.tv/archives/etv/>. After 23 years at the University of Texas at Austin, Newcomb became the Director of the George Foster Peabody Awards in $2001<\mathrm{http}: / / \mathrm{www}$. peabody.uga.edu/>. The Awards are housed in the Grady College of Journalism and Mass Communication at the University of Georgia, where Newcomb holds the Lambdin Kay Chair for the Peabodys and is Professor of Telecommunications. He teaches in the areas of television studies and screenwriting. Here, Newcomb joins Tara McPherson in a free ranging conversation on the history of television studies, the changing media landscape in the era of the internet, and the role of television in everyday experience.

Tara McPherson: I know you have written a little bit about how you came to the career that you have, but I thought it would be a good idea for the $e$-Media audience to hear about how someone who in the late 1960s studied American Lit at University of Chicago ended up being one of our premier television scholars. How did you blaze that trail? Even forty years later, I don't think that the University of Chicago has an established television studies program of any kind.

Horace Newcomb: No, I don't think so, and I don't know if I would have taken that route had it been there. A handful of us used to sit around the coffee shop in the Modern Languages Reading Area at Chicago and say, we should really be up at Northwestern studying movies; we knew they were doing it, and we didn't have anything. Gerald Mast didn't arrive at Chicago until well after I had left which was in '68, and, John Cawelti <http://www.research.uky.edu/odyssey/ spring00/popularlit.html > had just taught his first course on popular culture during my last year. As you said, I've written about some of these things elsewhere and tend to repeat the details. I can't remember if Cawelti's was undergraduate or graduate, I can't remember what quarter it was taught, but I do know that he asked to teach a course on popular culture and the chair of the English Department said, "Can't you at least call it literature and popular culture?" I sat in on it, and I had also taken a course with him during my second quarter at Chicago on late 19th century American Cultural History. My Masters was not in English; it was in a special program at Chicago, General Studies in the Humanities, pulling together literature and art and art history; in 
Cawelti's course, for example, we spent a lot of time studying Chicago itself in the 1890s, and so it all kind of came together.

The group I was part of made a bet at one point about which one of us would last the longest without publishing anything. You know, it was '68, and we were not enamored completely of the life of the university, and most of us were doing some minor politics and that kind of thing. But, some time during my first or second year of teaching, I noticed that Cawelti was chairing a session for the Midwest Modern Language Association on literature and the other arts. By that time it was '69, and I had begun to think more about television. I watched a lot of television. I am a sucker for story, and I love fictional narrative, and it had been a major part of my home life from when I was about 12 and my family moved from a small town in Mississippi to Jackson. We lived in the suburbs, and there was no way to get to a movie or anything. We were perfect examples of privatized mobility, and my family watched TV each night. In college I watched a good bit off and on, and so I kind of had these ideas about how television told stories and why those stories were important, because I had seen some interesting things there. When that call came from Cawelti for the MMLA I wrote a paper called "The problem of repetition in television," where I essentially said that I didn't like these stories that repeat themselves all the time. He sent me a manuscript for what would become his great book, The Six-Gun Mystique, and he also encouraged me to write more about soap opera and seriality, which I had mentioned as a counter example to the repetition.

In 1970 I moved from a small college in Iowa to a brand new college in Saginaw, Michigan where the goal was to create a radical humanities curriculum as they built the college from the ground up. During these years, I read just about everything that looked at TV from a humanities point of view. By that time I was sucked in to studying television. There wasn't much to use, however, so I collected most of it and sent around a proposal to do what would become The Critical View <http://www.jstor.org/view/0010096x/ap020121/02a00250/0>. One Doubleday editor suggested to drop the anthology idea and do a monograph on television, a turn that led to The Most Popular Art, where the work on soap opera appeared with chapters on other genres. I then moved on to Baltimore in 1972, to the University of Maryland-Baltimore County. The book was finished there.

Tara McPherson: What was the reaction to the book?

Horace Newcomb: A lot of it was positive. It must have been the cheapest book in America at \$2.50. In 1976 I got asked to return to Chicago as a fellow at a National Humanities Institute on Technology and Culture, and one of the senior people there was Roger Abrahams, who was Head of the English Department at the University of Texas in Austin. He invited me to apply for a job in English at Texas, and I went there in '78. I moved to Radio-TV-Film a few years later.

Nothing I've done would have been done so easily and perhaps as well without the support of the Radio-Television-Film department at Texas. Everyone there welcomed the sort of work I did and do and the courses that I wanted to teach. Among a great group of film scholars, production faculty, social scientists and specialists in international communication, television studies took its place and made Texas a place where those who wanted to study television from a humanities perspective would be welcomed and supported. I've also been lucky to work with a great group of graduate students over the years. Much of my work took on a decidedly 
collaborative tone as so many strong grad students passed through our program. I was able to direct or, most often, co-direct with Tom Schatz, or serve on the committees for an outstanding list of people still making major contributions to the field.

Tara McPherson: There is so much in that history you just recounted that seems to be replaying itself today in different but related ways. TV: The Most Popular Art was widely available and disseminated. Seriality was a key emerging conceptual paradigm. Universities were studying technology, culture, and the humanities. Many of my colleagues and students would imagine those traits to be hallmarks of the moment we live in today. I wonder if you have any thoughts on things like "citizen journalism" or what Henry Jenkins calls participatory culture today, and on how we might better understand what led us to these kinds of movements?

Horace Newcomb: I think we are in a moment of the most profound change in the media industries that we have had since either the invention of broadcasting or the transition to television, and it's altering everything from the business to the creative prospects, to the creative practices, the usability and so on. Jenkins has had some very interesting ideas on new types of curriculum that are needed, and the problem of course would be getting any department to really think through what that means. I have long since stopped trying to reform higher education and to alter the views of colleagues and administrators. We work in a context that's very slow to change. This has value; I like the fact that universities are in many ways an anchor that drags across the floor of some mucky ocean. But, I think we are going to change faster because the students are changing. I think things like citizen journalism and so on have huge benefits and huge problems.

I do not read blogs for example; I probably will have to at some point. We all know the problems of journalism generally are so great, that this has got to happen. There has to be some way to provide different voices and different kinds of information, particularly in moments of high politics as we are now in. The country is in worse shape than I have seen it in my life, so I think that those voices may come to mean something. Participatory culture is a fine idea. The problem that I always see is that I don't know who is going to watch, who is going to be the audience. In the mid '80s, I thought Paul Hirsch and I had sort of nailed television with the 'cultural forum' idea, but we did not realize that at that very moment the whole idea was already coming apart.

Tara McPherson: I was just about to ask you about that. If today's media landscape isn't a cultural forum, how would you describe it?

Horace Newcomb: I think it is now something like a library or a news stand or some place where you just go and roam. If I go to The Food Network, it's not that I go and just stay there; it's like when I go to a bookstore and go down the aisle for cook books, and I pull off one book on Southern Italian cuisine and ignore the others. I can then hop over to The Comedy Channel and pick up something else. Then on to $F X$, and so on. I just make up my own recipes. This selective browsing really has the business scared; they don't know how to handle this.

Tara McPherson: I'm fascinated by your comment that you don't read blogs. I do, but I find many of them very narrowly focused and even self indulgent. There have been interesting 
studies suggesting, that while things like list-serves created conversation between people who wouldn't normally speak to each other, blogs actually tend to attract very like-minded viewers and act as tightly circumscribed silos of knowledge, really the opposite of a broad cultural forum.

Horace Newcomb: Compared to blogs and even with all its liabilities and commercial impulses, I still maintain that television of an earlier era gave us varying views, admittedly within a limited range. But there were still things that you were forced to see, if you chose to watch, that you would not have seen otherwise. You had to confront your ideas and that's what has changed.

Tara McPherson: I find the notion that television's function as a cultural forum has waned within the post-cable, internet era particularly interesting when contrasted to the idea of participatory culture. So, at the very moment that individuals feel like they have more and more choice and freedom, the actual possibilities for broad cultural conversations among people with different ideas seem harder to imagine.

Horace Newcomb: Oh absolutely. I think the search for self-confirmation is really what's driving a lot of this.

Tara McPherson: Your work with Hirsch on TV as a cultural forum has been influential for years for many scholars teaching television.

Horace Newcomb: Well, people largely disagreed with it by the way!

Tara McPherson: It did pair beautifully in The Critical View with Todd Gitlin's piece. Some of the best conversations in my Intro to Television classes always came out of the pairing of those two essays. I was sorry to see it disappear from the latest edition of the anthology. Can you comment on that?

Horace Newcomb: I guess I could have put it in with all of this kind of conversation about the internet framing it, but I try to address some of this in my essay on The Sopranos that's in the current edition. The anthology has been an interesting project whenever I decide to redo it. In the beginning it largely included things from general reader magazines because there wasn't very much academic work. Over the years it's become very academic, which is both a good and bad thing, I think.

Tara McPherson: I also seem to recall that in the first edition of the anthology that, in addition to the popular journalism, wasn't there also Adorno's piece on television $<$ http://www.mediamatic.net/article-5813-en.html>?

Horace Newcomb: Yes, it's in there. I had found that essay, and, coming out of an English Department, at that time I had no idea of Adorno's significance. I just thought it was another good piece to put in there. I have thought on occasion of printing the tables of contents of all the previous editions in the back of each new edition. 
Tara McPherson: That's a great idea, because the anthology itself is a kind of history of the study of television over the years. I know that, from the Peabody Awards to working with the AFI, you have worked in close proximity to the TV industry in various ways. I would love to hear more about what you see as the benefits or possible drawbacks to academics actually engaging with the cultural workers in the industry.

Horace Newcomb: I think it's not a bad idea at all for people to know what people in the industry do. I've always argued, as John Caldwell does, that they are in their own way theorists, that they have assumptions about what they do and why they do it, and about how the media industries work. If pressed a little bit, they can articulate those quite nicely, once they get past the usual "Oh, it's just entertainment" part. I also like the seminars that the Television Academy does, and I noticed that IRTS (International Radio and Television Society) is moving one of their seminars out to the west coast, and I think that's very valuable for people. The Peabody Awards are actually an opportunity to "talk back" to the industries, helping to recognize strong work and in some ways helping to set standards. I enjoy my five minutes of commentary at our awards presentation ceremony each year in New York. And I appreciate the respect given to our awards process by the industries at large.

Tara McPherson: Maybe you could talk a bit about the Peabody Awards in relation to that? Can you talk about the mission of the Awards and about how you see the Awards changing in the era of digital media?

Horace Newcomb: The Awards were created in the late 1930s; the first awards were given in ' 41 for work done in 1940. They are the oldest awards for electronic media in the world. The National Association of Broadcasters <http://www.nab.org/> was a cofounder of the Award with the University of Georgia. The NAB is no longer affiliated. The awards were first, of course, for radio and in those days they were given more to stations than to program content, often for public service work. Because things weren't recorded, there were listening posts around the country; women's clubs did a lot of listening, and it was organized through the NAB. The first TV award was 1948. The awards gradually took on a kind of prestige, focused on service and wholesomeness and so on. In the 70s, we had some of the first awards for comedies, moving into new ground, although early comedians like Ed Wynn had received Peabody Awards. Now, we are very cognizant of having to move forward and do all sorts of things. From the '70s forward nothing has been considered out of bounds. We are still the only award that crosses media and gives awards in news, documentary, entertainment, education and so on, across the range of electronic media. The year that I came to the program, the Peabody board had decided to start accepting web entries, and so we have very carefully and cautiously tip-toed into that area. We have now given three awards to free standing websites, the first one, three years ago and two this year, and we skipped a couple of years where we didn't do any. We now get 40 or 50 entries a year, compared to our total number of radio and TV entries which number about 1000-1100 every year.

I don't know what would happen if everybody who put something on YouTube decided to pay the entry fee and submit! But, we will definitely have to continue to expand to the internet, and we are also becoming much more international. We have had some more submissions from other countries lately, and we want to increase that too. But the mission is the 
same, and it goes to the question that you started with, I enjoy working closely with industry issues and being able to say what kind of works we think are notable or important. We say the Peabody Awards have one criterion, which is excellence. That is defined as excellence on its own terms. Each piece sets up some kind of expectations, and those that really perform and meet those expectations are terrific works. The process of making the decisions is all done in face-toface deliberation, and it's just the most amazing kind of conversation about media, the role of the media, and the nature of excellence. It's also important to note that in the initial reviews of works submitted, we have committees of faculty and students. Each year at least 30 students participate in the Peabody process. It's a great teaching/learning experience.

Tara McPherson: I want to go back to the idea of seriality you mentioned earlier, particularly in soap opera. Do you see a kind of resurgence of seriality, perhaps prompted by the dispersed ways media is distributed now? It seems to be a particularly relevant concept for everything from "quality" TV shows like 24 , to reality television, to cell phone mobile service right now.

Horace Newcomb: I don't know if I would call it a resurgence as much as a discovery. It began for me in the late 70s with Hill Street Blues <http://www.museum.tv/archives/etv/H/ htmlH/hillstreetb/hillstreetb.htm> and Dallas <http://www.ultimatedallas.com/>, when the prime time programmers and producers realized that they could tell continuing stories at night. I was just looking at some of the trade stuff this morning on the web and one of the network people was saying that "what we are trying to do is balance between serialized fiction that requires people to make a commitment and episodic fiction which allows them a sense of satisfaction after one episode." That balance is the tricky part of programming, which means the tricky part of commissioning and pitching and everything else. I do think that Reality TV and the other forms you mention are very much based on that notion, of a continuing story and of continuing to go back to that. The reasons for me are fairly straightforward but also fairly deep; that is, we see the consequences of choices, we anticipate choices, we know so much more than the characters do. And we watch them make a choice, and we are sitting here and saying, "Oh no, oh no, this is not going to be good!", and with Reality TV we [are] probably playing some of that same game. I think the reality thing is here to stay, and there will always be seriality in television. It's a function of broadcasting, it's a function of the technology and the way it's organized-culturally, economically. Whether it's in an advertiser supported or even in state supported television system, you are trying to get people to come back, and seriality is a great technique for that.

Tara McPherson: Ironically, shows like American Idol might be the space where the most lingering effect of television as a cultural forum is created and sustained, at least at an affective or emotional level. Of course, in that venue, it's harder to see the representation of different views of the political as you outline them in your work on the cultural forum.

Horace Newcomb: We [Sara Newcomb and I] got hooked on Project Runway last year. I finally, of course, had to explain it to myself. I think part of my fascination was that they made things, that there was a product, and, for me, that was different from just watching The Osbournes, which was always great fun. I enjoyed seeing what they produced-I'm a believer in 
making things, I used to go over to the architecture school and just walk through, so I could smell glue and wood and things like that.

Tara McPherson: I really think that one of the things new media has done is make it much more conceivable and tangible to people that they might make things and also make things over. The whole resurgence of DIY culture that many of my students are part of right now seems a kind of feedback loop from the malleability of information on our desktops. The ease with which we move digital data seems to be fueling a desire to change and makeover material things.

I'm interested in your various engagements with the digital. Do you ever watch television on your iPod?

Horace Newcomb: I have never used an iPod. I have one that I received as an AFI juror, and it's still in the box. I'm not so much into music. It's interesting because our son is a terrific musician and professional guitar player and song writer and singer, and I'll go home and pop in a jazz CD and sit there and sip a drink, but music has never been a daily part of my life. I don't listen to the radio much either.

Tara McPherson: I now watch TV on my iPod when flying. At first, I thought I would mourn the loss of a big screen and the home setting, but portability and mobility have completely won me over. Do you use a Tivo or DVR? How has it altered your viewing and experience of TV?

Horace Newcomb: Certainly the way we watch TV has changed in terms of timeshifting and not knowing precise schedules of when something airs.

Tara McPherson: We tend to stockpile episodes at our house and watch several in a row. That's definitely diminished the water cooler effect. In the light of changes like these, wrought by digital media, I wondered what you think about the future of a project like The Encyclopedia of Television?

Horace Newcomb: My guess is that a lot of reference books are going to go online pretty soon and be updated on a regular basis.

Tara McPherson: Perhaps some kind of Wikipedia-style version?

Horace Newcomb: I haven't looked at Wikipedia to see what kinds of entries there are on things like television programs. I know there is an entry on the Peabody Awards <http://en.wikipedia.org/wiki/Peabody_Award>, and I occasionally look at it, and often something new is there. That certainly would be a way to go, particularly if there were some combination of a Wiki, the TV Encyclopedia and a journal like Flow <http://www.flowtv.org/>. It could be interesting to have a commentary or forum element there.

Tara McPherson: It also seems that new digital technologies have animated a whole host of questions regarding archives and historical memory. I know that libraries are very 
interested in this topic, from preservation to issues of opening up the archive. Is this something you are addressing at Peabody?

Horace Newcomb: Yes, very much so. We hosted a meeting recently that brought together a group of television and media historians to meet with media archivists. We had about a dozen people here from the archives group, and we had about a half dozen historians as well. It was interesting, because the archivists were sort of surprised when they learned that the historians wanted paper records as well as preserved media. You have to wonder how the archive will transform in the future. These are really big questions: how do we archive this, how do we preserve it, how do we make use of it.

I am not a historian, but I have become more interested in the whole archival process since coming to Georgia. The Peabody Archive is not under my administration, it's under the UGA libraries, but we work very closely together. We want more scholars to come here and work in our archive and are trying to make funds available for that. It is a unique archive, because it is self-selected by the people who submit; it's what they have perceived to be their best work. What people don't know is that it's not a collection of the winners, it's a collection of the entrants. We don't have them from the early days, of course, but the collection slowly began to pick up with the late '60s forward. We have 45,000 plus in titles of radio and television, mostly television, and we we've got multiple episodes of many titles. Entrants often send us an entire season. It's really rich. One of my favorite examples is that, since it went on the air, there have been something like 60 individual stories submitted by 60 Minutes. I think they have won maybe eight or nine Peabody Awards (and there is one this year). You could look at what they submitted as their best work and then you could look at what the board thought was really the best of the best out of that; you could do all sorts of comparative studies like that.

Tara McPherson: And really look at the thematics and topics that cut across a year or genre.

Horace Newcomb: Yes, it's definitely a cross section. Early on we had local television news but also certainly in earlier days some local programming, like children's programming. We probably have the best collection of local television news in existence. In addition to a great deal of local news we still occasionally get a local documentary, a 30 minute piece or something like that. It ranges from public TV-type programming to truly independent work. We gave an award a couple of years ago to a little piece for children that's just distributed directly-by direct video and DVD sale.

Tara McPherson: Have you seen an increase at all in local media production? At least one of the oft-repeated hopes of our moment of "participatory culture" is that self-distribution and independent media forms will flourish again.

Horace Newcomb: No, we don't see much of that, but this year particularly we saw a lot of strong local news stories. Some years we have had to kind of fish for them. But this year we saw some great work, and four stations are getting awards, two in Indianapolis. This has never happened outside of New York or Washington or the like, two stations in a smaller market receiving the Peabody Award for local programming. I don't know of very much that's truly 
independent locally. Some of the radio material we have was done by independent producers that are not directly affiliated with an NPR station. Another big problem we face: we don't get much commercial radio, in part because of the huge group ownership and pre-programmed content.

Tara McPherson: The archive sounds amazingly rich. How are you moving ahead now?

Horace Newcomb: Our librarians are working very, very hard to get a version of a catalog online and are close. It's not a completely marked record, and they are continuing to do that. On our own website we have a searchable list of all the winners through the years, each with a written citation. The early citations were very brief, but we are now putting a great deal of information in the citations, such as names of producers and writers and cast. We're experimenting with the best kinds of search information.

Much of the archive itself is very fragile. We think it would probably take 15 to 20 million dollars to digitize the whole collection. The library is also doing some specific grantfunded projects. All the entries related to the Civil Rights movement and African-American experience for example, are fully catalogued. That was done a while ago with NEH grants.

Tara McPherson: Let's zoom scale a bit here and shift from the local to the global. You mentioned earlier that you've seen an increase at Peabody in international submissions. On the one hand, there seems to be proliferation of all kinds of low-barrier-to-entry self-publications and then, at the other end, an increasing consolidation of media empires on a global scale.

Horace Newcomb: I have not seen a proliferation in independent voices apart from some aspects of the web. There may be an increase of a truly individualized kind of voice online, a kind of niche voice like we discussed before. Within the commercial media or even in public service media, I make a couple of distinctions. One is between news and information on one side and entertainment on the other. I have never had as many choices for entertainment as I have now. That's what I like and what I study, so, I don't see consolidation as having a negative effect there. In terms of news, it's probably a different story, although even there I see more kinds of views and more kinds of information are out there in terms of sheer quantity. And, as I always remind people in seminars, that proliferation means a lot of stuff you might disagree with too. FOX News certainly is not my cup of tea, but there are certainly a lot of people watching who thought they never had a voice before and that they are now being spoken to. I guess that's the troubling part of a diversity of voices.

Tara McPherson: And the second distinction?

Horace Newcomb: The other distinction I make is that I have never accepted a direct line between ownership and creative control, particularly on the entertainment side, although this is less firm in terms of the news side. There have been cases where we know that newsrooms were forced to take different kinds of lines or not run stories. On the entertainment side, I've just watched too much of the ways in which creative people evade control and get other points of view across. It's a tricky balance, but it happens. That's where I disagree with some of the more straight-line consolidation criticism that goes on; I think it's over-simplified at times. Still, I think we have to be cognizant of consolidation and its effects, even if it's not a total picture. There are 
some places where consolidation has actually been helpful as in South Africa where some owners bought up stations to do counter or alternative kinds of programming.

Tara McPherson: Let's move on from here and speak some more about media, history and memory, tying together some strands from across this interview. At one point, you claimed not to be a historian but spoke quite eloquently about archives and their roles in public life. You've also commented here and in earlier writing on the role television played in your own coming of age, about its role in personal and public memory and in the crafting of the self. A few years ago, I came across an article you had written for The Austin Chronicle <http://www.austinchronicle.com/gyrobase/Issue/story?oid=oid\%3A76176> about a George Wallace documentary. It's a lovely piece, and in it you detail the regional specificity of your memories of media, and your own coming to activism during the Civil Rights movement. Could you talk a little bit about that moment in history and if you see media today providing similar opportunities for young people to engage pressing political issues?

Horace Newcomb: I'm very proud of that piece. I think it's one of the better things I have ever written, and most of my writing now does take a kind of autobiographical cast.

Tara McPherson: That's very southern of you!

Horace Newcomb: Yes, it's a regional, indigenous disease that we carry with us in the world. You know, we used to have ringworms and things like that, but not anymore. Memory disease is incurable. But, I actually think that growing up in the South and watching TV there was pretty central to my whole career in a way that I didn't realize for a while.

When I taught at the University of Texas, I used to give an assignment in my undergraduate classes for people to write a television autobiography. Students began to write about all sorts of things, not just "what did you see and when did you see it," but really getting at how they lived with TV, what it meant to their families, etc., and they were so rich. It was about that time that I realized that-and I don't know why this had not really floated to consciousness before-television really did change my views about race and region and politics and so on. Moreover, it was the fictional programming that did it, not the news. It was The Defenders <http://www.museum.tv/archives/etv/D/htmlD/defendersth/defendersth.htm>, and it was Route 66 <http://www.tv.com/route-66/show/1044/summary.html>, and it was Matt Dillon defending the Chinese laundryman from a lynch mob. I was an English major in college and even before that I was reading widely. I was growing up in Mississippi, but there was another world out there. The deep South at that time was such a closed society. I graduated from high school in 1960, and, when you think back to the '50s and even well into the '60s, that time was so defined by race and religion. I didn't believe exactly what they said in church on Sunday, but what I was reading in the Gospels had a kind of radical potential. I did go to movies too, especially when I was very young and lived in a small town in north Mississippi with a movie theater two doors down from the little cafe that my dad owned. I would go to the movies pretty much whenever I wanted to then. But it was the TV that most expanded my perspective. Fictional TV in the 1960s has been misrepresented by pretty much everybody except Mark Alvey who really delved into that. There was a lot going on regarding race in the '60s on TV, even on shows like The Beverly Hillbillies <http://www.tv.com/beverly-hillbillies/show/1370/summary.html>. 
Tara McPherson: Right. And you were, of course, watching these shows through the lens of a boy coming of age in the south in a very turbulent and violent period.

Horace Newcomb: Yes. Seeing those issues really on the surface of the shows, I think, made a lot of difference for me. Now, in college, I didn't watch a lot of television because I worked at night most of the time. But I'm quite convinced that television changed my attitude. I remember having a late night conversation with Todd Gitlin one night at an ICA meeting or somewhere. He said something like, "Well look, if that's the power of fictional television, why didn't it affect everybody in Mississippi in the same way?" Of course, it was just one stimulus; there were all sorts of other things going on for me and for other people as well. There were people who were never going to change, and those were the people I began to argue with quite strenuously. I never did a great deal of Civil Rights work in Mississippi, but I was involved a little bit there.

Tara McPherson: I love that this narrative and your writing about that time allow us to connect the dots between Route 66 and the journey you've made, both in life and as a television scholar. That's a really important vector to be able to understand. The earlier piece is quite eloquent, and I hope you don't mind if I read a bit of your writing back to you?

You wrote, "The only thing that matters now is that we be forced to remember. It is not history we need. It is memory. History is the tutor of memory. History is memory educated." I know you are still an avid watcher of television, and I wonder if there are any contemporary programs you would want to single out that are now serving a comparable function to those shows from the sixties for our own politically troubling times?

Horace Newcomb: I watched Boston Legal last night, and was amazed that David Kelly was taking on the government and the war straight on and by name. While some might say that the comedic elements of the show undercut the critique, I'd say that, for some viewers, a show like this is going to be it. That's going to be the place where they make a decision that this war is so wrong, so unnecessary, so destructive, so bloody, so debilitating, and so tragic for so many people. It could have been avoided. And this whole issue was taken up on a fictional television show in this serial comic form. The performances were great, and Kelly is a great writer, all the way back to Picket Fences. In Boston Legal, he uses the courtroom as the forum. Given that the networks are so much more dispersed post-cable, I think that Kelly and other writers are freer now than they would have been 10 or 15 years ago to do this kind of thing, and it's more explicit. Of course there are also moments in shows like ER and The West Wing, as well as in The Sopranos. I'm not just talking about the war, I'm talking about the whole political realm that is part of our lives, and I think that the fragmentation of the programming and the segmentation of the audience might actually make these moments of critique more possible.

Now the big question is whether somebody who is a major supporter of the war could watch an episode like that one of Boston Legal and experience a change of heart. They could just tune it out, they could choose to watch other things, they could literally isolate themselves from the counter point of view for the most part. Still, I think that with more and more people being killed and so on, it's going to be harder to avoid the counter-viewpoint. I do think one reason there may not be a more organized antiwar effort is because we are not forced to watch one of 
three networks every night and that we can avoid so much by watching something else. There is no authoritative core, no cultural center as there was in the 1960s. I don't want to romanticize that, it was a very repressive core in so many ways, but now you can choose to avoid ever seeing much about the war or you can express your opinions in a very fragmented media sphere.

Tara McPherson: So, the fragmenting of the media realm really cuts both ways: you can perhaps get away with a bit more on the programming side but you also have to deal with a splintered audience. There's no real national audience any more. Still, I do think that my own father-in-law's political opinions were changed by his exposure to Jon Stewart and The Daily Show. He began watching it while visiting us before the 2004 election, and the series became part of a larger shift in political point of view for him. While I wouldn't say the show singlehandedly changed his mind, its comedy became a way for him to articulate his own growing dissatisfaction with the Bush administration.

Horace Newcomb: Yes, and that may be happening more than we know. The real question of course is the one that people who take a stronger line than I do always come back to: how does it translate into action and what kind? I do know that television affected how I understand the world. And I finally figured out that's ultimately the reason why I study television, because it really did force me to change my life back in my teens. I think that's true for others as well.

Tara McPherson is Associate Professor of Critical Studies in USC's School of Cinematic Arts. She is co-editor of Hop on Pop: The Politics and Pleasures of Popular Culture, editor of Digital Youth, Innovation and the Unexpected, and author of Reconstructing Dixie: Race, Gender and Nostalgia in the Imagined South, as well as numerous essays. She is editor of Vectors, $a$ multimedia journal <http://www.vectorsjournal.org >; publishing only work that can't exist in print, and co-editor of a forthcoming MacArthur-supported journal on digital media and learning (MIT Press, 2009).

Published by the Dartmouth College Library.
Copyright $\odot 2008$ Trustees of Dartmouth College.
http://journals.dartmouth.edu/joems/
Article DOI: 10.1349/PS1.1938-6060.A.320

